\title{
A MITLEIDSETHIK E OS ANIMAIS OU SCHOPENHAUER COMO PRECURSOR DA ÉTICA ANIMAL
}

THE MITLEIDSETHIK AND THE ANIMALS OR SCHOPENHAUER AS A PRECURSOR OF THE ANIMAL ETHICS

\author{
JAIR BARBOZA \\ (PUCPR - Brazil / Humboldt-Stiftung, Germany)
}

\begin{abstract}
Resumo
Este artigo tem por objetivo mostrar que Schopenhauer, mediante sua Mitleidsethik (ética da compaixão), baseada numa metafísica da Vontade de vida, pode ser visto como um precursor da ética animal.

Palavras-chave: Metafísica da Vontade, Ética da compaixão, Schopenhauer.
\end{abstract}

\begin{abstract}
This article aims to show that Schopenhauer, by means of a Mitleidsethik (ethics of compassion), based in a metaphysics of Will to live, can be seen as a precursor of the animal ethics.

Keywords: Metaphysics of Will, Ethics of compassion, Schopenhauer.
\end{abstract}

\section{Tradição}

A tradição consagrada da filosofia ocidental decerto é fortemente marcada pela orientação racionalista, que na matemática encontra o seu modelo; algo exemplarmente exposto por Platão na República, em que as matemáticas dão acesso ao mundo das Idéias eternas, arquétipos deste mundo sensível, temporal, de simulacros e sombras. A aritmética e a geometria conduzem à verdade, pois ocupam-se com aquilo que sempre é e nunca vem-a-ser. ${ }^{1}$ Razão e mundo harmonizam-se no desvelamento metafísico do ser, para além das imagens transitórias da caverna em que vivemos. A faculdade racional, parte boa da alma em oposição aos sentimentos, segundo o próprio Platão, deve reger a estes, e desse modo nos conduzir ao sentido das coisas. Em realidade tem-se já aqui uma ordem numérico-espacial da natureza que poderia perfeitamente ser pensada como um primeiro esboço da ciência universal cartesiana da ordem e medida, ou seja, a chamada mathesis universalis. ${ }^{2}$

A razão é vista desde a Academia, passando pela aurora da filosofia moderna, não só como aquilo que diz corretamente o mundo, mas também como aquilo que diferencia o homem do animal. Uma diferença que levou Descartes a alertar em seu Discurso do método que, após o erro dos que negam Deus, não há outro que "mais afaste os espíritos fracos do caminho reto da virtude que imaginar que a alma dos animais é da mesma natureza que a nossa". ${ }^{3} \mathrm{O}$ autor ainda formula explicitamente, na quinta parte de sua obra, que o estudo das ciências tem por objetivo nos tornar "como que mestres e possuidores da natureza". ${ }^{4}$ Eis um pensamento que no seu extremo em muito deve ter contribuído para a destruição da natureza (e para a crueldade contra os animais) observados 
em nossos dias e que levou Adorno e Horkheimer a alertarem que o iluminismo se relaciona com as coisas "como o ditador relaciona-se com as pessoas", ou seja, "só as conhece na medida em que são manipuláveis". 5

Tempos depois Kant não deixará de seguir tais passos platônico-cartesianos no sentido da separação entre um observador e a natureza como seu objeto, em verdade alvo do próprio projeto iluminista de desmistificação do mundo, com concomitante domínio instrumental dele. De fato, uma das imagens mais famosas de Kant, apresentada na primeira crítica, é a de que o investigador vai até a natureza não na condição de aluno para ser por ela instruído, mas na de juiz que dela exige respostas às suas questões. Quanto aos animais, a Fundamentação da metafísica dos costumes os classifica como "coisas", diferentemente dos homens, que são "pessoas". Estas são um fim em si mesmas, não podem ser usadas, ou seja, são dignas, enquanto as coisas podem ser meio para um fim.

Compreende-se por tais marcos que não é comum à tradição debruçar-se sobre o tema da dignidade dos animais, sobre o direito deles, visto que separa cuidadosamente a substância racional pensante, o homem, da substância extensa, a natureza exterior como objeto.

\section{Metafísica da Vontade}

Ora, na contramão dessa vertente clássica, posiciona-se a assim chamada Mitleidsethik, ética da compaixão de Schopenhauer. Para compreendê-la, contudo, é antes necessário situá-la no interior de sua metafísica, cuja marca registrada é justamente a inversão da tradição, no sentido de que, se antes a razão era primária e a chave de acesso à ordem e medida do mundo, ao seu sentido mesmo, em Schopenhauer ao contrário o sentimento é que dá acesso ao Em-si do mundo, primariamente irracional, isto é, pura vontade, a razão sendo secundária, mero momento desta. A vontade é a substância íntima do homem e o conhecimento surge para ele como "instrumento" de sobrevivência do seu complexo organismo, num mundo cheio de adversidades cujos golpes podem sem avisar torná-lo nada.

Ele se CONHECE, portanto, em conseqüência e em conformidade à índole de
sua vontade, em vez de, segundo a antiga visão, QUERER em conseqüência e
em conformidade ao seu conhecer. De acordo com esta antiga visão, ele precisa
apenas ponderar COMO prefere ser, e seria: isto é a liberdade da vontade; logo,
ela consiste, propriamente dizendo, no fato de o homem ser sua própria obra, à
luz do conhecimento. Eu, contrariamente, digo que o homem é sua própria obra
antes de todo conhecimento, e este é meramente adicionado para iluminá-la. Daí
não poder decidir ser isto ou aquilo, nem tornar-se outrem, mas É de uma vez por
todas, e sucessivamente conhece o QUÊ é. Pela citada tradição, ele QUER o que
conhece; em mim ele CONHECE o que quer. [Schopenhauer, 2005, p. 379]

É uma vontade dada no corpo do investigador, que por sua vez não é uma "cabeça 
alada de anjo", mas, no limite de sua subjetividade encontra-se como ser dotado de vontade, além da qual não pode ir. A autoconsciência, dessa forma, não passaria da percepção de uma base volitiva do próprio caráter, de maneira que a vontade percebida como o em-si do corpo pode depois ser estendida analogicamente não só a todas as outras possíveis consciências, mas também a todos os corpos da natureza, sejam eles orgânicos ou inorgânicos. Noutros termos, analogamente ao meu corpo os outros corpos são concretude do querer. Conforme a metafísica da natureza de $O$ mundo como vontade e como representação, exposta em sua segunda parte (que, em verdade, é uma espécie de cosmologia), o querer como a coisa-em-si una e indivisível está em todos os fenômenos do cosmo, na força que forma o cristal, na seiva da planta, na agulha magnética apontada para o pólo norte, nas forças de atração e repulsão, na gravidade que faz a pedra cair etc. Em tudo isso, embora diferente nos fenômenos dados no espaço e no tempo e submetidos à lei de causalidade, "é para se reconhecer como aquilo conhecido imediatamente de maneira tão íntima e melhor que qualquer outra coisa e que, ali onde aparece do modo mais nítido, chama-se VONTADE." "É a Vontade cósmica que em toda parte quer viver. Vontade de vida, Wille zum Leben: essência-identidade dos seres, indestrutível para além da pluralidade da representação, e da diferença percebida na efetividade pelo entendimento, cuja forma básica é o princípio de razão que separa os seres, já que este é constituído pelo espaço que permite posicionamentos diferenciados dos objetos, e pelo tempo que permite a sua sucessão. Numa palavra, tem-se aí o chamado princípio de individuação, a separar fenomenicamente, para a percepção, o que em-si é uno. O filósofo se refere a esse processo de fragmentação como a visão das coisas pelo "Véu de Maya" da existência que, ao nos fazer tomar a pluralidade por verdadeira, isola egoisticamente o eu e o não-eu, sujeito e objeto, espectador e mundo. Todavia, metafisicamente, os seres têm uma única essência. $\mathrm{O}$ animal inclusive possui entendimento, com o qual forma suas intuições empíricas do mundo e assim sobrevive com o conhecimento tanto quanto o homem. Ele percebe, pois, o perigo, o sofrimento possível, e consegue assim fugir dele. A diferença em relação ao homem é que este, a partir das representações intuitivas, forma as representações abstratas da razão, e adquire conceitos universais das coisas, uma visão de conjunto que o animal não tem. Todavia, os animais têm uma mesma essência, a Vontade de vida, e uma mesma forma de operar o entendimento, como no caso daquele elefante, citado por Schopenhauer, que depois de atravessar, numa caravana, várias pontes numa jornada pela Europa, recusou-se a entrar numa outra ponte, pois ela lhe parecia (num cálculo automático do entendimento) muito frágil para o seu peso.

\section{Preconceito especista}

Sendo assim, é precisamente no contexto dessa metafísica da Vontade, aqui traçada em seus contornos gerais, que se deve compreender o lugar da ética e dos animais no pensamento de Schopenhauer. Como se pode observar na obra tardia Parerga e paralipomena, $\S 177$, o autor é um ácido crítico do modo como a cultura ocidental trata os nossos "irmãos" animais. A crítica 
vem a par da, por assim dizer, arqueologia teórica do preconceito relacionado ao animal tornado objeto, cujas camadas mais profundas o filósofo identifica no Gênesis bíblico, especialmente nos capítulos 1 e 9. É daí que, segundo ele, decorre o "erro fundamental" do cristianismo, influenciado pelo judaísmo, que separou de maneira "antinatural" os seres humanos do mundo animal, "ao qual ele pertence essencialmente". Desse modo, formou-se século a século uma tradição que influenciou os mais diversos setores da cultura no Ocidente, na direção de considerar os animais como objetos manipuláveis. No Gênesis essa nulidade é comprovada pelo fato de não haver recomendação de bons tratos para com eles, de maneira que seriam posses destinadas aos homens, os quais poderiam "imperar" sobre os mesmos como quisessem. ${ }^{7}$ Seguiu-se daí a aparentemente natural ausência do direito animal. Embora o filósofo considere a ética do Novo Testamento, baseada na virtude da compaixão, elogiável - pois tal sentimento diminui a maldade inata do homem - ainda assim a critica por limitar seus preceitos aos homens, deixando os animais desabrigados de direitos.

Esse preconceito bíblico sedimenta-se na mentalidade do povo, que muitas vezes maltrata animais gratuitamente, infligindo-lhes graves e cruéis injúrias, ou os mata mediante tortura, em vista de simples divertimento. A conclusão do autor é cáustica: "Poder-se-ia verdadeiramente dizer: os seres humanos são o diabo sofre a face da terra e os animais são as almas por ele flageladas." " Diversão satânica tanto mais triste porque contra a violência dos ignorantes, afirma, só o medo neles criado pela religião, ou o medo da polícia. Mas nesse caso o pensamento religioso judaicocristão falhou, restando para amparo dos animais apenas a polícia, ou as sociedades protetoras dos animais, cujo nascimento o filósofo testemunhava com aplauso. O mencionado preconceito sedimenta-se em camadas cada vez mais densas e o gênero humano, com o tempo, "vê a natureza como um instrumento". Isto cava um abismo entre sujeito e objeto, investigador e natureza, cuja face terrível se mostra nos experimentos inúteis em que os animais são imolados no "altar da ciência". São as vivissecações e as câmaras de tortura dos "medicastros", muitas vezes em experimentos para resolver problemas cuja solução há tempos se encontra nos livros. A denúncia e indignação do autor chega ao ponto de acusar a falta de formação humanística dos médicos, num diagnóstico de surpreendente atualidade, haja vista uma medicina cada vez mais excludente dos que não têm dinheiro, pois é cara devido à tecnologia para reparar efeitos de doenças, em vez de combater as suas causas, precisamente porque é antes orientada para o lucro.

\footnotetext{
Nossos médicos não têm mais a clássica formação de antigamente, que lhes conferia uma certa humanidade e um traço nobre. Hoje em dia tudo ocorre o mais cedo possível na universidade, onde se trata apenas de aprender o próprio ganha-pão, para assim prosperar sobre a terra. [Schopenhauer, 1986, p. 441]
}

Na rubrica dessa razão instrumental, Schopenhauer cita o exemplo do orgulhoso Barão Ernst von Bibra que planejou, e levou ao seu termo, para "uso da ciência", matar por inanição dois 
coelhos com o objetivo de investigar se por tal tipo de morte os componentes químicos do cérebro sofreriam uma alteração. Indignado, o filósofo afirma que, antes de serem químicos, os cientistas são pessoas, e pergunta como tais pesquisadores podem dormir de consciência tranqüila, muitas vezes ao terem arrancado filhotes de sua mãe para os deixar assim sofrer. Uma pergunta que nos dias de hoje poderíamos colocar aos pesquisadores que trabalham nas indústrias de cosméticos e farmacêuticas, bem como aos médicos que, sedentos por reconhecimento na comunidade científica, realizam experimentos duvidosos para encontrar soluções que ou poderiam ser obtidas por outros meios ou já estão, como o filósofo mesmo afirma, em livros.

A própria filosofia seria uma camada sedimentada do preconceito judaico-cristão aqui examinado. Na linha cartesiana, em Kant, diz Schopenhauer, os animais são "coisas", conforme o filósofo de Königsberg se refere a eles na Fundamentação da metafísica dos costumes. Mas, como se observou, toda coisa pode ser considerada um "meio" para um fim, portanto pode ser manipulável, ao contrário do ser racional, que é "um fim em si mesmo" e desse modo é digno em sua autonomia e liberdade, vale dizer, é de fato uma pessoa. No entanto a obra do filósofo de Königsbeg sobre a qual Schopenhauer debruça-se com mais sutileza para mostrar o preconceito especista é a Metaphysischen Anfangsgründen der Tugendlehre. Aqui a passagem primeiro destacada é a do $\S 16$, na qual é dito que o homem não tem obrigação de dever para com outros seres senão para com os humanos. Em seguida, o autor aponta a passagem do $\S 17$ na qual Kant diz que evitar o tratamento cruel de animais é dever do homem, entretanto só "para consigo mesmo", ou seja, para impedir que a compaixão seja abafada, pois a mesma se mostra útil para o trato com outras pessoas. Schopenhauer declara tais passagens, em meio a toda uma admiração que tinha pelo gênio de seu mestre, como "revoltantes e nojentas" porque recusa aos animais o direito de serem considerados como dignos, fins em si mesmos. Afinal de contas eles têm corpo dotado de cérebro e sensibilidade, que ativa um sistema nervoso que identifica o sofrimento, num processo de defesa da vida semelhante ao do homem. Schopenhauer termina por concluir que a filosofia kantiana, aqui, é uma teologia travestida, enraizada na Bíblia que abandonou os animais ao arbítrio humano, tornando-os meios para quaisquer fins, como costumeiramente se deu na cultura ocidental: "caçadas, luta de touros, corridas de aposta etc." Numa passagem depois usada por Nietzsche para também referir-se à (para ambos os autores portanto) moral de escravos kantiana, Schopenhauer diz: "Pfui! sobre uma tal moral de Parias-Tschandalas-Mlekhas". O ponto decisivo da argumentação é particularmente importante para a ética animal contemporânea, ou seja, Schopenhauer acusa essa moral de observar apenas o valor da própria espécie, die eigene werthe Species, como se o fato de o homem possuir uma faculdade racional distinguisse essencialmente a sua espécie das outras e assim lhe conferisse direitos excepcionais sobre os demais corpos animais. ${ }^{9}$ Aqui vale em Schopenhauer o que Bentham disse, numa frase muito citada: “a questão não é se eles possuem razão ou se podem falar, mas, podem eles sofrer?"'10

Esse exame arqueológico do milenar preconceito contra os animais dirige-se por fim ao 
sedimento da linguagem, em particular da língua alemã. $O$ filósofo chama a atenção para o fato de a faculdade racional e o seu desdobramento, exatamente a linguagem - pois linguagem e razão e confundem na filosofia de $O$ mundo... ${ }^{11}$ - procurar sob a diferença de termos esconder a identidade essencial dos seres. Assim, em alemão, quando o ser humano come, emprega-se para tal ato o verbo essen, enquanto para os animais o verbo empregado é fressen; quando os humanos bebem o verbo usado é trinken, já para os animais é saufen; se de um lado os humanos fazem sexo, Sex haben, os animais, por outro, begatten sich; e se para o nascer de uma criança se tem o verbo gebären, para os animais se tem werfen; o cadáver humano é nomeado Leiche, o cadáver animal Kadaver. Apesar de a língua inglesa ser menos discriminatória nesse aspecto, ainda assim os animais são referidos pelo pronome neutro $\mathrm{I} t$, ao lado de coisas inanimadas em geral.

Contrapondo-se a tais separações milenares, a metafísica schopenhauereana, alicerçada na identidade da Vontade de vida como coisa-em-si una e indivisível de todos os seres, concebe os animais como partícipes de uma sensibilidade comum ao homem, logo, dispondo da mesma capacidade, no caso de animais complexos, de perceber e sentir com consciência o sofrimento corporal. Dessa perspectiva, é um erro levar em conta eticamente apenas o valor da própria espécie: o que em realidade ocorreu na ciência, na medicina, na filosofia, na religião, na linguagem, enfim, na cultura ocidental sob a égide do Gênesis que permite aos homens imperar sobre os animais, verdadeiros corpos-máquinas. Mas a conclusão do Parerga e paralipomena é incisiva:

Todos os sentidos precisam estar completamente cegos ... para não perceberem que $o$ animal é no fundamento e em essência absolutamente o mesmo que nós somos e que a diferença reside apenas no acidente, o intelecto, não na substância, que é a Vontade. O mundo não é uma obra de segunda categoria e os animais não são uma mercadoria (Fabrikat) para o nosso uso. [Schopenhauer, 1986, p. 443]

\section{Mitleidsethik}

É no contexto dessa metafísica da Vontade que Schopenhauer insere a sua ética, trabalhada de maneira pormenorizada em Sobre o fundamento da moral. O tema dos animais é ali inteiramente concebido no horizonte da Mitleidsethik, da ética que aponta a compaixão como o núcleo de toda ação virtuosa. É uma ética que denuncia, com todos os termos, a violência e a crueldade advinda da ilusão separacionista entre eu e não-eu, investigador e mundo, sujeito e objeto, numa palavra, trata-se de um pensamento que examina até onde leva a cegueira do egoísmo colossal do homem.

Desde já, observe-se que a ética aqui abordada elege, como conceito operador de sua reflexão sobre a virtude praticada em relação a outrem, não o ser racional, como no caso da kantiana, 
mas antes "todos os seres vivos", alle lebenden Wesen. O grande monstro a ser aí combatido, como mola impulsora do que é anti-moral, é o egoísmo que provoca dor, sofrimento a outra vida na sua desenfreada busca pelo próprio bem-estar, mesmo se às custas do mundo inteiro. É o homem soldado na guerra de todos contra todos. Por conseqüência, ali onde o egoísmo for efetivamente neutralizado, tem-se, por negação, uma boa ação, visto que há diminuição do sofrimento de um ser vivo.

\begin{abstract}
O egoísmo, de acordo com sua natureza, é sem limites: o homem quer conservar incondicionalmente sua existência, a quer incondicionalmente livre da dor, à qual também pertencem toda penúria e privação, quer a maior soma possível de bemestar, quer todo prazer de que é capaz, e procura ainda desenvolver em si novas capacidades de prazer. Tudo o que contraria o esforço de seu egoísmo provoca sua má vontade, ira, ódio, e procurará aniquilá-lo como se fosse seu inimigo. Quer se possível desfrutar tudo, possuir tudo. Ora, como isso é impossível, quer pelo menos dominar tudo. "Tudo para mim e nada para os outros" é a sua palavra de ordem. O egoísmo é colossal, ele comanda o mundo. Pois se fosse dado a cada indivíduo a escolha entre a própria aniquilação ou a do mundo, não precisaria dizer para onde a maioria se inclinaria. [Schopenhauer, 2007, pp. 94-5]
\end{abstract}

É unicamente na compaixão que Schopenhauer identifica o poder, a mola impulsora das ações humanas capaz de neutralizar esse egoísmo colossal. É ela que, desinteressadamente, procura de fato o bem-estar alheio. Em realidade, trata-se do fenômeno diário - embora, diga-se, não corriqueiro - da participação independente e imediata, sem cálculos, no sofrimento de outrem e, daí, a ajuda efetiva para diminuí-lo ou extingui-lo, às vezes com o custo da própria vida. À medida que essa compaixão é despertada, o estado sofrente de outrem atinge imediatamente o coração do agente e o impele a praticar uma ajuda, mediante a qual de fato o selo daquele sentimento é estampado em sua conduta. Da compaixão, conforme Sobre o fundamento da moral, decorrem as virtudes cardeais da justiça desinteressada e da caridade.

No entanto a compaixão não é um Sollen, um dever imperativo, mesmo porque a vontade, um sentimento, não pode ser ensinado, mas é um dispositivo natural, vale dizer, uma "participação instintiva" no sofrimento alheio. Trata-se de uma "compaixão natural" que, infira-se, apresenta-se na forma de um mecanismo de que a natureza se serve para impedir o holocausto do gênero humano. A diferença entre eu e não-eu, tão real para o egoísta, é anulada via conhecimento. Vê-se através da pluralidade. Porém, não obstante a sentida identidade essencial a que leva esse sentimento, quem age por ele sabe, acentua o filósofo, que a parte passiva é um outro e não ele em possível situação semelhante no futuro, por conseguinte não age porque se vê ali como objeto da compaixão alheia (o que significaria implicitamente o egoísmo reintroduzido pelas portas do fundo). Nesse horizonte, a ética da compaixão critica o imperativo categórico de Kant, pois quando este sentencia que devemos agir de tal maneira que a nossa ação se transforme numa lei universal, exemplifica dizendo que, se não o fizermos, como no caso de ações contraditórias - por exemplo, pegar dinheiro emprestado 
com a falsa promessa de devolvê-lo -, poderemos ser pagos com a mesma moeda. Todavia isto seria um modo egoístico de proceder, nos vendo como a parte passiva em semelhantes condições. Portanto, em vista de evitar o perigo da heteronomia, Schopenhauer, diferentemente, sublinha: ao agente compassivo fica a todo momento claro que o outro é, sem dúvida, quem sofre; o agente não sofre na própria pessoa o sofrimento alheio, mas sofre imediatamente no outro mesmo, com ele, e nesse momento vê através do princípio de individuação, isto é, descobre a unidade metafísica da Vontade em meio à pluralidade fenomênica. $\mathrm{O}$ eu sofre no não-eu, todavia para além da diferença entre eu e não-eu sente uma única vida.

Sofremos COM ele, portanto EM sua pessoa: sentimos sua dor como SUA e não temos a ilusão de que seja nossa: em verdade, quanto mais feliz o nosso próprio estado e assim quanto mais a consciência do mesmo contrasta com a situação do outro, tanto mais somos receptivos à compaixão. [Schopenhauer, 2007, p. 110]

Tal poder de levar outrem em incondicional e desinteressada consideração, para além do próprio e natural egoísmo, fonte de tanta violência, é o que faz Schopenhauer nomear a compaixão, Mit-leid (padecimento-com, paixão-com), o único fundamento da ética e portanto das ações virtuosas. Tal sentimento faz uma profunda declaração de paz em relação a todo não-eu, evitando a guerra incontrolável de todos contra todos. Apesar de cotidiana, retenha-se, não é comum. E mais: embora salte aos olhos, é "misteriosa"; embora não imperativa, pois é um sentimento, pode-se dela extrair uma pedagogia da não-violência para abrandar a belicosidade do homem; embora não-conceitual, é mediada pelo conhecimento, já que o agente sabe a todo momento que age em favor de outrem.

Por conseguinte, ao apontar o que julga ser o fundamento da ética, Schopenhauer, trabalhando com as noções primárias de "corpo animal" e "ser vivo", ancoradas na visão de uma única Vontade cósmica de vida, considera os animais sujeitos morais tanto quanto os homens. $\mathrm{O}$ que lhe permite denunciar os "sistemas morais europeus" que não tomaram os mesmos sob sua proteção. Ao contrário, sua ética é extensível a todo ser vivo capaz de sofrimento e afirma que, quem se coloca no lugar de um animal necessitado, para assim ajudá-lo e salvá-lo, decerto dá sinais de ser uma boa pessoa. "Compaixão com animais está tão estreitamente associada à bondade de caráter que se pode afirmar confiantemente que, quem é cruel com animais, não pode ser uma boa pessoa." ${ }^{12}$ Nesse contexto o filósofo narra aqueles elogiáveis e pedagógicos casos de pessoas em seu dia-a-dia, ou caçadores, que subitamente descobrem a capacidade de sofrimento dos seres nãoracionais e não mais os maltratam, ou os caçam. São pessoas que sentem remorso ao se lembrarem que, num acesso de mau humor, maltrataram seu cão, seu cavalo ou seu macaco - a chamada "voz da consciência punitiva". Há o caso de um caçador inglês, narra o filósofo, que numa caçada na Índia não pôde esquecer o olhar que um macaco lhe lançou antes de ser abatido a tiros; desde então nunca mais atirou em macacos. Outro caso é o de um caçador de elefantes que, depois de haver 
matado um elefante fêmea e procurar o animal morto no dia seguinte, encontrou o seu solitário filhote, o qual passara a noite ao lado da mãe morta: ao ver o caçador, o filhote se dirigiu a ele em sua dor inconsolável e o enlaçou com a pequena tromba: o caçador sentiu um profundo remorso, como se tivera cometido um assassinato.

Em tais casos Schopenhauer aponta o surgimento súbito da compaixão em pessoas que maltratavam ou matavam animais, portanto até então insensíveis para com eles, descobrindo subitamente que aquele outro corpo não é uma coisa, porém uma vida sujeita a sofrimento. Casos que de um lado ilustram a irrupção natural da Mitleid e de outro mostram como, do exame de casos a envolver essa consideração ética do sofrimento alheio, pode-se extrair uma pedagogia da nãoviolência e fazer uma denúncia do preconceito judaico-cristão contra os animais, sobre os quais o homem estaria autorizado a imperar, sem qualquer recomendação de bons tratos. Segue-se daí a exigência de direito dos mesmos enquanto corpos sensíveis, tanto quanto os humanos. Em realidade, trata-se nessa ética e pedagogia de, ao mesmo tempo, exigir a quitação de uma dívida milenar que o Ocidente tem para com os nossos "irmãos".

Dessa perspectiva o filósofo, ao colocar a ética na base do direito, fala explicitamente de "direito dos animais", Rechte der Tiere, ou seja, os animais como detentores imediatos de direitos naturais ao bem-estar e ao respeito, tanto quanto o homem. Daí, sintomaticamente, a sua viva atenção para as sociedades protetoras de animais que surgiam na época (séc. XIX), em função do que os ingleses são elogiados por as terem fundado. Com alegria secreta o filósofo relata a notícia lida num jornal inglês, de dezembro de 1839, pela qual reporta-se que a sociedade dos amigos dos animais acionou a polícia para deter um grupo que planejava uma briga de cães. Quando integrantes do grupo chegaram ao local foram surpreendidos e presos. Ao final tiveram de desembolsar uma boa soma em dinheiro para se verem livres, caso contrário seriam condenados a quatorze dias de trabalho forçado. Outro caso é retirado do Times, de 6 de abril de 1855, pelo qual relata-se que uma moça torturou a faca o seu cavalo, e por isso teve de pagar uma quantia considerável, sob a pressão do jornal, que estampou em letras garrafais o seu nome e sobrenome.

\section{Conclusão}

Em síntese, a Mitleidsethik faz a arqueologia do milenar preconceito judaico-cristão que toma os animais como coisas manipuláveis, numa visão geral de que a natureza estaria aí para o nosso uso. O que diferenciaria o homem do animal, a faculdade de razão, torna-se um instrumento de domínio do outro, da outra vida, sem que a questão sobre a dor corporal e o sofrimento sejam considerados relevantes. Uma razão, por conseqüência, fria e cega na sua separação entre sujeito e objeto - num projeto de domínio identificado pelo filósofo lá no Gênesis bíblico, cuja ausência de 
recomendação de cuidados para com os animais repercute na mentalidade do povo, na ciência, na medicina, na filosofia e até mesmo na linguagem (alemã e inglesa). Ora, a partir de uma metafísica na qual o corpo animal é o conceito-chave e a base para uma ética da compaixão, sentimento que desvela a unidade dos seres para além da ilusão da pluralidade, o autor defende que os seres vivos não-racionais são também sujeitos morais.

Entretanto, seu pensamento não vai tão longe a ponto de desembocar no elogio do vegetarianismo. Empenha-se antes em condenar o maltrato e a crueldade contra os animais, não a renúncia à sua carne. $\mathrm{O}$ argumento utilitarista empregado é que a morte rápida e indolor dos mesmos causaria menos sofrimento do que aquele sentido pelo homem ao ficar sem comer carne, especialmente no hemisfério norte. Ao fim dessa equação favorável aos humanos, recomenda um abate rápido e indolor. Uma equação que também valeria para o trabalho animal, apesar de Schopenhauer ter condenado a escravidão humana.

Que decerto a compaixão com animais não tem de conduzir tão longe a ponto de,
como os brâmanes, renunciarmos à alimentação animal, baseia-se no fato de que
na natureza a capacidade para o sofrimento aumenta com a inteligência; pelo que o
homem, ao ser privado da alimentação animal, sobretudo no norte, sofreria muito
mais que o animal através de uma morte rápida e imprevista, a qual seria ainda
mais facilitada por meio do clorofórmio. Sem alimentação animal, ao contrário, o
gênero humano não poderia sequer sobreviver no norte. Segundo o mesmo critério
o homem faz o animal trabalhar para si, e apenas o excesso da exigência torna-se
crueldade. [Schopenhauer, 2007, p. 144]

Estamos, pois, diante de uma ética animal mitigada. Dizer que os homens, por conta de sua inteligência que aumenta a capacidade de sofrimento, ao ficarem sem comer carne sofreriam mais que os animais abatidos, é algo já na época duvidoso, como mostram os acima citados vegetarianos brâmanes, aos quais se junta um naquela época incipiente movimento de vegetarianos entre os ingleses, também citado pelo próprio autor em Parerga $\S 177$. Esse argumento em favor da alimentação animal é tanto mais questionável porque a própria ética da compaixão, ancorada na unidade da Vontade de vida, é extensível a todo corpo capaz de sofrer e ter ciência do sofrimento pelo entendimento, isto é, pela faculdade de intuição, e é por isto que o autor condena a vivissecação e as câmaras de tortura dos medicastros. Parece-me que neste aspecto o autor não é totalmente coerente com as premissas de sua metafísica e de fato ainda se prende, aqui, à tradição filosófica, ao conferir prerrogativas ao homem consciente, dotado de inteligência racional, que reflete sobre o passado, o presente e o futuro e, desse modo, ao adquirir uma visão de conjunto da vida, aumenta a sua capacidade de sofrer, como a ligada ao pensamento de não comer carne. Segue-se daí um certo privilégio em face do animal não-racional, que não dispõe dessa visão de conjunto. Mas, se na metafísica da Vontade o relevante do ponto de vista de uma justificativa ética da dignidade do sujeito é o fato de uma única e mesma essência pulsar em todo ser vivo, concretizada em corpo, 
e se isto permite ao filósofo fazer a defesa do direito dos animais a uma vida sem maus tratos, por que então argumenta em termos utilitaristas, quando afirma que o homem, sem a alimentação à base de carne, sofreria mais que o animal submetido a um abate súbito e indolor? A resposta só pode ser: por causa da razão que calcula. Schopenhauer, portanto, na passagem acima citada, toma a inteligência na acepção de atividade da faculdade racional. Porém neste caso o argumento utilitarista considera de maneira forte a diferença entre ser racional e ser não-racional, e a acentua como relevante no caso de se decidir entre as duas formas de sofrimento mencionadas. Contudo, a metafísica schopenhauereana já havia neutralizado a relevância metafísica e ética dessa diferença, ao apontar a identidade dos corpos animais, habitados por uma única e mesma essência, a Vontade de vida, a razão humana sendo secundária. ${ }^{13}$

Se de um lado é flagrante esse problema das conclusões que não satisfazem completamente as premissas fundamentais do seu sistema, de outro lado, a ética da compaixão de Schopenhauer, que inclui os animais, é sem dúvida ímpar e inovadora na história dos grandes sistemas metafísicos do Ocidente. O reconhecimento e elogio dessa visão são imperativos. Além do mais nota-se em suas obras uma paulatina radicalização das conclusões na direção do estabelecimento de uma coerência interna de seu pensamento ético com o Mundo como vontade e como representação, de 1818, na qual os animais são concebidos mais sob a lupa da teoria do conhecimento, no sentido de possuírem entendimento tanto quanto o homem. Contudo, em Sobre o fundamento da moral, de 1840, a compaixão é estendida aos animais e, na obra tardia Parerga e paralipomena, de 1851, encontrase uma refinada arqueologia do preconceito judaico-cristão contra os mesmos que marca não só a visão fria da ciência experimental, mas também a posição teórica dos sistemas morais europeus. Desse modo, podemos afirmar, Schopenhauer de fato é um precursor da ética animal. E, em vista dessa linha de radicalização, talvez não fosse descabido imaginar que, se tivesse testemunhado a produção industrial de carne, na maior parte das vezes com o transporte bárbaro de animais para depois serem trancafiados em verdadeiros campos de concentração à espera do abate, concluísse o que a sua metafísica da Vontade e a sua Mitleidsethik exigiam, ou seja, que o "corpo animal" como "ser vivo" e dotado de vontade, portanto passível de sofrimento a ser negado, é o sujeito da ética; não o ser-racional, e neste sentido é o fator relevante no exame do direito à dignidade da existência. 
Notas

${ }^{1}$ PLATÃO. The Republic. Trans. By Tom Griffith. Cambridge: Cambridge University Press, 2000, $524 \mathrm{~b} ; 527$ b.

${ }^{2}$ DESCARTES. Regulae ad directionem ingenii. Hamburg: Felix Meiner, 1973, regra 4, pp. 23-7;173.

${ }^{3}$ Idem, Discours de la methode. Hamburg: Felix Meiner, 1969, V, p. 96.

${ }^{4}$ Idem, ibidem, VI, p. 100.

${ }^{5}$ ADORNO, T; HORKHEIMER, M. Dialektik der Aufkärung. Frankfurt: S.Fischer, 1969, p. 15.

${ }^{6}$ SCHOPENHAUER. O mundo como vontade e como representação. Trad. Jair Barboza. São Paulo: Ed. Unesp, 2005 , p. 168.

${ }^{7}$ Com efeito, Lutero, em sua tradução de 1545, provavelmente a lida por Schopenhauer, emprega o termo herrschen, imperar, dominar os animais, quando verte os versículos 1, 26 e 1, 28 do Gênesis, os quais, juntados ao versículo 9, 2 mostram que a imagem dos animais não-humanos ali presente é a de um ser que tem de ficar submisso e apavorado diante do homem, como por outro lado este também tem de ficar submisso e apavorado diante de Deus. Portanto, Deus está para os homens como os homens estão para os animais, ou seja, o homem seria o senhor dos animais. Na tradução de Lutero lemos em 1, 26: Und Gott sprach: Laßt uns Menschen machen, ein Bild, das uns gleich sei, die da herrschen über die Fische im Meer und über die Vögel unter dem Himmel und über das Vieh und über die ganze Erde und über alles Gewürm, das auf Erden kreucht. "E disse Deus: Façamos o homem à nossa imagem, conforme a nossa semelhança; e domine sobre os peixes do mar, e sobre as aves dos céus, e sobre o gado, e sobre toda a terra, e sobre todo o réptil que se move sobre a terra" (Trad. Almeida, 1994. Fonte: http://www.bibliaonline.com.br). Ora, após ter criado o homem e a mulher à sua imagem e semelhança, Deus lhes diz 1,28: Seid fruchtbar und mehret euch und füllet die Erde und macht sie euch untertan, und herrschet über Fische im Meer und über Vögel unter dem Himmel und über alles Tier, das auf Erden kreucht. "Frutificai e multiplicai-vos, e enchei a terra, e sujeitai-a; e dominai sobre os peixes do mar e sobre as aves dos céus, e sobre todo o animal que se move sobre a terra." (trad. cit.). Por fim, o versículo 9, 2 dá o retoque final nessa imagem do animal-coisa manipulável (em verdade a natureza inteira): Eure Furcht und Schrecken sei über alle Tiere auf Erden, über alle Vögel unter dem Himmel und über alles, was auf dem Erdboden kreucht; und alle Fische im Meer seien in eure Hände gegeben. "E o temor de vós e o pavor de vós virão sobre todo o animal da terra, e sobre toda a ave dos céus; tudo o que se move sobre a terra, e todos os peixes do mar, nas vossas mãos são entregues." (trad. cit.) Tudo entregue em mãos humanas; todavia a recomendação de bom trato não é acrescentada. O que fica, portanto, é a imagem do animal medroso e submisso para uso do homem.

${ }^{8}$ Idem, "Parerga und Paralipomena II". In: Sämtliche Werke, edição Löhneysen. Suhrkamp: Frankfurt, 1986, p. 439.

${ }^{9}$ Idem, Über die Grundlage der Moral. Hamburg: Felix Meiner, 2007, p. 61.

${ }^{10}$ Apud WOLF, J-C. "Willensmetaphysik und Tierethik". In: Schopenhauer-Jahbuch. 79. Band. Königshausen/ Neumann: Würzburg, 1998, p. 87.

${ }^{11}$ A razão forma representações de representações, os conceitos, e com isso permite a linguagem, a comunicação, a ação planejada, entre outros. "Enquanto o animal comunica sua sensação e disposição por gestos e sons, o homem comunica seus pensamentos aos outros mediante a linguagem, ou os oculta por ela. Linguagem que é o primeiro produto e instrumento necessário da razão. Por isso, em grego e italiano, linguagem e razão são indicadas com a mesma palavra: lógos, il discorso. Vernunft, razão, vem de Vernehmen, inteligir, que não é sinônimo de Hören, ouvir, mas significa a conscientização de pensamentos comunicados por palavras. “

[Schopenhauer, 2005, pp. 83-4.].

${ }^{12}$ Idem, Über die Grundlage der Moral. Felix Meiner: Hamburg, 2007, p. 141.

${ }^{13}$ Cf. WOLF, J-C. Ibid, p. 93. 


\section{Referências}

ADORNO, T; HORKHEIMER, M. Dialektik der Aufkärung. Frankfurt: S.Fischer, 1969.

DESCARTES. Regulae ad directionem ingenii. Hamburg: Felix Meiner, 1973.

PLATÃO. The Republic. Trans. By Tom Griffith. Cambridge: Cambridge University Press, 2000.

SCHOPENHAUER. Sämtliche Werke. Edição Löhneysen. Suhrkamp: Frankfurt, 1986.

. O mundo como vontade e como representação. Trad. Jair Barboza. São Paulo: Ed.

Unesp, 2005.

. Über die Grundlage der Moral. Hamburg: Felix Meiner, 2007.

WOLF, J-C. "Willensmetaphysik und Tierethik". In.: Schopenhauer-Jahbuch. 79. Band. Königshausen/Neumann: Würzburg, 1998. 